\title{
บUsisersily
}

\section{Spontaneous combustion coal parameters for the Crossing-Point Temperature (CPT) method in a Temperature-Programmed System (TPS)}

Xu, Y., Wang, L., Tian, N., Zhang, J., Yu, M., \& Delichatsios, M. A. (2017). Spontaneous combustion coal parameters for the Crossing-Point Temperature (CPT) method in a Temperature-Programmed System (TPS). Fire Safety Journal, 91, 147-154. https://doi.org/10.1016/j.firesaf.2017.03.084

Link to publication record in Ulster University Research Portal

\section{Published in:}

Fire Safety Journal

Publication Status:

Published (in print/issue): 17/07/2017

DOI:

10.1016/j.firesaf.2017.03.084

\section{Document Version}

Author Accepted version

\section{General rights}

Copyright for the publications made accessible via Ulster University's Research Portal is retained by the author(s) and / or other copyright owners and it is a condition of accessing these publications that users recognise and abide by the legal requirements associated with these rights.

\section{Take down policy}

The Research Portal is Ulster University's institutional repository that provides access to Ulster's research outputs. Every effort has been made to ensure that content in the Research Portal does not infringe any person's rights, or applicable UK laws. If you discover content in the Research Portal that you believe breaches copyright or violates any law, please contact pure-support@ulster.ac.uk. 


\title{
Spontaneous combustion coal parameters for the Crossing- Point Temperature (CPT) method in a Temperature- Programmed System (TPS)
}

\author{
Yong-liang XU1,2,3 ${ }^{*}$, Lan-yun WANG ${ }^{1,3}$, Ning TIAN², Jian-ping ZHANG², Ming-gao YU ${ }^{1,3}$, Michael \\ A. Delichatsios ${ }^{4}$ * \\ ${ }^{1}$ College of Safety Science \& Engineering, Henan Polytechnic University, Jiaozuo 454003, \\ China; \\ ${ }^{2}$ FireSERT, School of the Built Environment, Ulster University, Newtownabbey BT37 0QB, UK; \\ ${ }^{3}$ Collaborative Innovation Center of Coal Safety Production of Henan Province, Jiaozuo 454003, \\ China;
}

${ }^{4}$ Senior Distinguished Research Fellow, Ulster University, Newtownabbey BT37 0QB, UK

\begin{abstract}
Coal fires originate from coal spontaneous combustion caused by oxidation starting even at low temperatures. In order to evaluate the heating and oxidation of coal placed inside a container, a TemperatureProgrammed System (TPS) is used under various flow and oxidation conditions for temperatures ranging from 40 to $250{ }^{\circ} \mathrm{C}$. As the coal samples are heated in the container within the TPS, the concentration histories of the gaseous products are measured as well as the temperature history at the center of the container. The Crossing-point Temperature (CPT) is the temperature (temperature and corresponding time) at which the increasing coal temperature is equal to the increasing oven temperature within the TPS. We have developed energy and oxygen mass conservation equations for the coal pile in a container inside the TPS oven assuming uniform conditions for temperature and oxygen concentrations, both assumptions partially justified because the heating rate in the oven is very low $\left(1{ }^{\circ} \mathrm{C} / \mathrm{min}\right)$. By subtracting the convective heat from the thermal inertia of the coal pile in the energy equation, we have obtained from the experimental data the heat owing to oxygen reaction or moisture evaporation. From the oxygen conservation and measurements, we have determined apparent activation energy and pre-exponential factor for oxidation assuming that oxidation is proportional to oxygen concentration. This information is useful for the mathematical modelling of oxidation and heating in the present experiments. Subsequently, the energy and mass conservation equations were solved after being transformed to non-dimensional form, which shows that four dimensionless parameters control the heating of coal in the present experiments. Only three of these parameters are examined in detail, namely a dimensionless flow time, a heat release parameter $B$, and a Damkohler number $D a$ whereas a moisture parameter is discussed qualitatively. Based on the present analysis and data, four stages are identified: (I) initial heating with essentially no reaction or evaporation, (II) evaporation period with essentially no reaction, (III) an unsteady accelerated oxidation period during which crossover may occur and (IV) a heating late period where all the oxygen reacts inside the container.
\end{abstract}

KEYWORDS: Spontaneous combustion of coal, endothermic stages, Crossing Point Temperature, a Damkohler number

\section{NOMENCLATURE LISTING}

$A \quad$ area of the container $\left(\mathrm{m}^{2}\right)$

$A_{0} \quad$ Arrhenius pre-exponential factor $\left(\mathrm{s}^{-1}\right)$

$C_{p} \quad$ specific heat capacity of coal at constant pressure $\left(\mathrm{J} / \mathrm{kg} /{ }^{\circ} \mathrm{C}\right)$

$E_{a} \quad$ apparent activation energy $(\mathrm{kJ} / \mathrm{mol})$

$h_{c} \quad$ heat transfer coefficient $\left(\mathrm{W} / \mathrm{m}^{2} /{ }^{\circ} \mathrm{C}\right)$

$\Delta H_{O_{2}} \quad$ reaction enthalpy of $\mathrm{O}_{2}(\mathrm{~kJ} / \mathrm{kg})$
$V \quad$ container volume $\left(\mathrm{m}^{3}\right)$
$Y_{O_{2}}$ mass fraction of oxygen $\left(\mathrm{kg}_{\mathrm{O}} / \mathrm{kgg}_{\mathrm{g}}\right)$
$Y_{O_{2}}^{0} \quad$ mass fraction of $\mathrm{O}_{2}$ of inlet gas $\left(\mathrm{kg}_{\mathrm{O} 2} / \mathrm{kgg}_{\mathrm{g}}\right)$

Greek

$\alpha \quad$ heating rate in the oven $\left({ }^{\circ} \mathrm{C} / \mathrm{s}\right)$

$\varnothing \quad$ the porosity of coal pile 
$\dot{m}$

mass flow rate of air into container $(\mathrm{kg} / \mathrm{s})$

$M \quad$ mass of coal in the container $(\mathrm{kg})$

$\dot{Q}_{r} \quad$ heat generation rate $(\mathrm{W})$

$r_{\mathrm{O}_{2}}$ rate of consumption of $\mathrm{O}_{2}$ per unit volume of coal $\mathrm{kg} /\left(\mathrm{m}^{3} \mathrm{~s}\right)$

$R \quad$ universal gas constant $(\mathrm{kJ} / \mathrm{mol} / \mathrm{K})$

$t \quad$ time since $40{ }^{\circ} \mathrm{C}$ in oven (s)

$T \quad$ absolute temperature of coal at time $t(\mathrm{~K})$

$T_{o v} \quad$ absolute temperature of oven at time $t(\mathrm{~K})$ $\rho_{p} \quad$ particle density of coal $\left(\mathrm{kg} / \mathrm{m}^{3}\right)$

$\rho_{b} \quad$ bulk density of coal $\left(\mathrm{kg} / \mathrm{m}^{3}\right)$

$\rho_{g} \quad$ gaseous density via coal particles $\left(\mathrm{kg} / \mathrm{m}^{3}\right)$

$\tau \quad$ thermal residence time

X dimensionless coal bed temperature

$\tilde{t} \quad$ dimensionless time

$B \quad$ normalised maximum heat release

$D_{a} \quad$ Damkohler number

\section{INTRODUCTION}

Coal fires in abandoned or inactive coal mines occur frequently in mining areas around the world [1-3]. Specifically, coal fires continue to be a serious global problem in surface coal mining as well as underground mines, especially in China where coal supplies more than $60 \%$ of its energy consumption. In addition, coal fires cause the loss of valuable coal resources and the release of large amounts of greenhouse gases (such as $\mathrm{CO}_{2} / \mathrm{CH}_{4}$ ) [4]. Furthermore, they also produce mine subsidence features like sinkholes and fractures [57], which degrade the geological and environmental background.

There are many experimental tests and theories to simulate the evolution of coal spontaneous combustion including small-scale and large-scale tests even on-site tests in coal mines and coal stockpiles. Note that large-scale and on-site tests require extensive money, time and human resources. Therefore, small-scale tests are widely used around the world to fundamentally assess spontaneous combustion of coal as briefly outlined next. Jones [8; 9] used a cubic basket method to analyze the heat-release rates and global kinetic parameters. Wang et al [10] utilized a fixed-bed flow reactor and applied a mathematical model to describe steady-state mass transfer and oxidation processes in coal at low temperatures. Zarrouk et al [11] applied a numerical method to solve the mass and heat transfer in adiabatic coal spontaneous combustion. Beamish et al [12-14] used an adiabatic method to assess the self-heating behavior and reaction parameters at low temperature. Li et al $[15 ; 16]$ tested the heat release intensity at low temperature and the shortest ignition time of coal spontaneous combustion with the hot-wire method. Chen and Chong [17], Sensogut and Cinar [18], and Wang et al [19-21] in succession proposed the Crossing-Point Temperature (CPT) method within various experimental systems to investigate heating and oxidation characteristics leading to spontaneous combustion of different kinds of coal. In addition some large scale tests were conducted by Deng et al [22] who constructed a 15-tone experimental furnace of coal spontaneous combustion to analyze the variations in temperature, so called index-gas ratios, oxygen consumption rate, heat intensity and establish the corresponding relationship between index-gas ratios and coal temperature. Fierro et al [23] prepared five test piles of $2000 \sim 3000$ tons built at a power station in Teruel (Spain) to examine various heat losses. These large-scale tests are not common because they need 3 4 months to conduct and use 15 20 tons of coal for each test.

The kinetics of coal oxidation at low temperatures have been researched based on experiments and simulations. Jones [8; 9] and Wang [10] presented the kinetic parameters $\left(A_{0}\right.$ and $\left.E_{a}\right)$ of oxidation including oxygen transport and gaseous species distribution in coal piles. Wang et al [24] studied the oxygen consumption, oxidation products, reaction mechanism and kinetic modeling at low temperatures of the coal oxidation. Zarrouk et al [11] developed a reaction model to predict the heat-release as an oxidation reaction by using usual Arrhenius parameters. Nimaje and Tripathy [25] proposed an index to assess the coal liability to spontaneous combustion. In [26-28], researchers examined the role of flow dynamics on the spontaneous combustion within an open stockpile using CFD simulations. In addition, other researchers have also studied the oxidation process and gaseous products under oxygen-lean conditions at low temperatures [29-31]. Note that the process of coal spontaneous combustion consists of oxygen absorption, mass weight gain/loss, 
oxidation, burn-off and finally coal combustion at high temperatures $\left(>400{ }^{\circ} \mathrm{C}\right)$. Zhan et al [31] proposed four stages of coal oxidation, namely water evaporation, oxygen chemisorption, significant decomposition reaction reactions and burn-off reaction, taking place up to $400{ }^{\circ} \mathrm{C}$ as determined by a TG/DTA data. Wang [21] brought forward three stages as slow oxidation stage $\left(<70^{\circ} \mathrm{C}\right)$, accelerated oxidation stage $\left(>140^{\circ} \mathrm{C}\right)$ and middle stage between them at low temperature coal oxidation .

Despite the previous extensive experimental and modeling research, coal spontaneous combustion cannot be described by single parameters, such as air flow, inlet oxygen concentration, porosity of coal particles, kinetic parameter (apparent activation energy and Arrhenius pre-exponential factor), ambient temperature, but small scale tests are still useful to compare the propensity for spontaneous ignition for different coals as well determine critical parameters. In order to evaluate the heating of arbitrary coal samples a TemperatureProgrammed System (TPS) is used (see Fig.1) under various flow and oxygen oxidation conditions for temperatures ranging from 40 to $250{ }^{\circ} \mathrm{C}$ as described in section 2. The Crossing-point Temperature (CPT) is the temperature at which the increasing coal temperature is equal to the increasing oven temperature in the TPS test, as discussed in section 3. We have developed a mathematical model based on the energy and oxygen mass conservation equations for the coal pile inside the container by assuming uniform conditions and same gas and coal temperature, both assumptions partially justified because the heating rate in the oven is very low $\left(1^{\circ} \mathrm{C} / \mathrm{min}\right)$, as discussed in section 4 .

\section{EXPERIMENTAL SYSTEMS AND METHODS}

\section{1 Temperature- programmed System (TPS)}

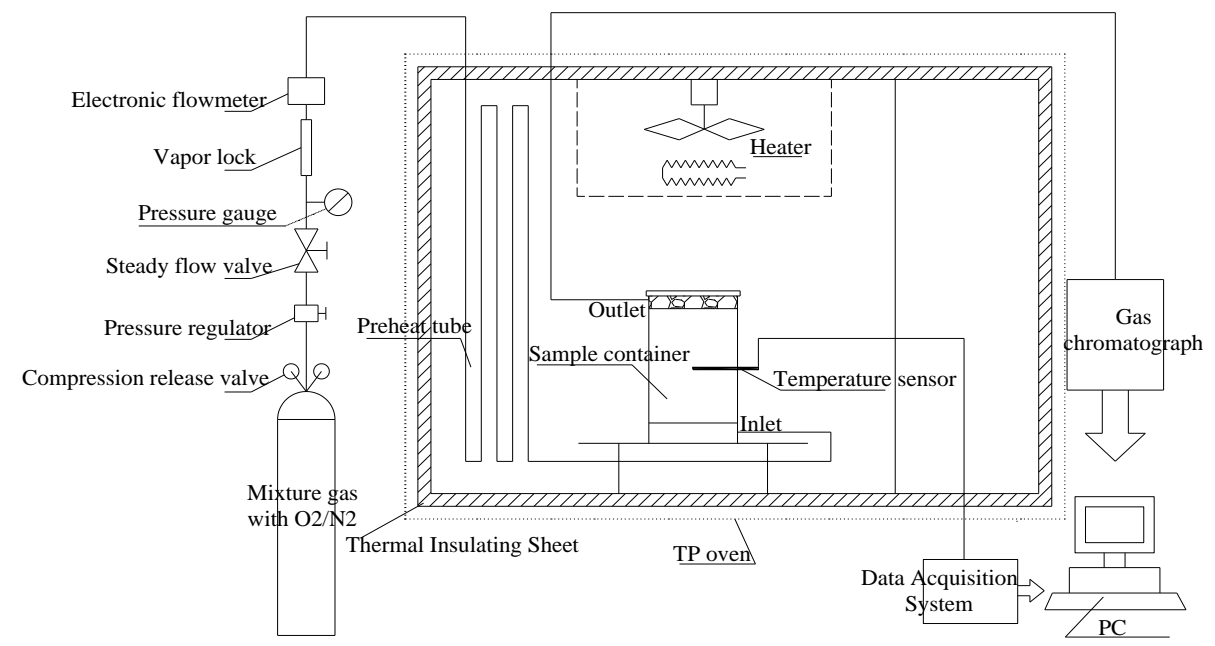

Fig.1 Experiment system for temperature programmed showing the oven, the coal container and the instrumentation

The temperature-programmed system (TPS) was used to determine the CPT in order to evaluate the oxidation behavior of bituminous coal. The TPS, shown in Fig.1, is composed of the TemperatureProgrammed (TP) oven, a sample cylindrical container (Diameter $=45 \mathrm{~mm}$, Height $=40 \mathrm{~mm}$ ) of stainless steel, a data acquisition system and a gas chromatography. Here, the TP oven, consisting of a heating device and a temperature sensor with an accuracy of $0.1{ }^{\circ} \mathrm{C}$, could automatically increase the oven temperature at a constant heating rate of $1{ }^{\circ} \mathrm{C} / \mathrm{min}$. The data acquisition system is used to acquire and record the temperature at the center of sample coal container at every 20 seconds. The gaseous products generated from the coal sample are separately analyzed by the gas chromatograph with an accuracy of $10^{-4} \mathrm{ppm}$ (see Fig. 1).

\section{2 Experimental Procedures}

\subsubsection{Preparation of coal samples}

A bituminous coal was collected from a coalfield in Inner Mongolia. The coal sample was crushed and ground into particles. Size distribution of the particles was measured using coal sieves and the volumetric 
average diameter of the coal was $0.3 \sim 0.45 \mathrm{~mm}$ having a total weight of $300 \mathrm{~g}$ for use in the present experiments. Prior to the tests, the coal particles were dried in a vacuum of $-0.05 \mathrm{MPa}$ (gauge pressure) at $30{ }^{\circ} \mathrm{C}$ for 12 hours. Table 1 tabulates the proximate and ultimate analysis of the coal samples.

Table 1. Proximate and ultimate analyses for the coal

\begin{tabular}{|l|c|c|r|}
\hline \multicolumn{2}{|c|}{ Proximate analysis (air-dry basis) } & \multicolumn{2}{c|}{ Ultimate analysis (dry ash free basis) } \\
\hline Moisture (\%) & 9.38 & $\mathrm{C} \mathrm{( \% )}$ & 68.15 \\
\hline Ash (\%) & 5.33 & $\mathrm{H} \mathrm{( \% )}$ & 5.89 \\
\hline Volatile matter (\%) & 31.26 & $\mathrm{~N} \mathrm{( \% )}$ & 0.78 \\
\hline Fixed Carbon (\%) & 54.03 & $\mathrm{~S} \mathrm{( \% )}$ & 0.91 \\
\hline & & $\mathrm{O} \mathrm{( \% )}$ & 9.56 \\
\hline
\end{tabular}

\subsubsection{Testing procedure in TPS}

For each test, $40 \mathrm{~g}$ of coal particles $(0.3-0.45 \mathrm{~mm})$ were placed in the cylindrical container. Then we turned on the data acquisition system for temperature and blew dry air to check gas tightness of pipelines of the TPS. Next the temperature-programmed equipment was started until the temperature of the coal sample reached $40{ }^{\circ} \mathrm{C}$ where it was kept for 60 minutes. Subsequently, the $\mathrm{O}_{2} / \mathrm{N}_{2}$ mixture flow, was applied at a flow rate of $80 \mathrm{ml} / \mathrm{min}$, containing $\mathrm{O}_{2}$ volume concentration of 20.65, 17.80, 13.62, 10.49, 5.00 and 3.00 vol\% while the heating rate of the oven was set as $1.0^{\circ} \mathrm{C} / \mathrm{min}$. Simultaneously the gas chromatography was activated and the significant gaseous products including $\mathrm{O}_{2}, \mathrm{~N}_{2}, \mathrm{CO}, \mathrm{CO}_{2}$ and $\mathrm{C}_{\mathrm{x}} \mathrm{H}_{\mathrm{y}}$ were measured every $10{ }^{\circ} \mathrm{C}$ (about $10 \mathrm{~min}$ ) from 40 to $250^{\circ} \mathrm{C}$. The measurement errors were less than $1 \%$ and each experiment was repeated three times having good reproducibility.

\section{3 TGA-DSC- experiments}

A TGA-DSC instrument was also used to evaluate the oxidation behavior of coal samples, and the one adopted was a NETZSCH STA 449C thermal analysis system with a nominal resolution of mass of $0.1 \mu \mathrm{g}$. Approximately $20 \mathrm{mg}$ of the coal sample which has particle diameters below $0.1 \mathrm{~mm}$ was placed in an $\mathrm{Al}_{2} \mathrm{O}_{3}$ crucible and heated up to $800{ }^{\circ} \mathrm{C}$ at heating rates of $10^{\circ} \mathrm{C} / \mathrm{min}$ from $20^{\circ} \mathrm{C}$. The gas flow of $\mathrm{O}_{2} / \mathrm{N}_{2}$ mixture was set at $80 \mathrm{ml} / \mathrm{min}$ containing oxygen at $10,14,18$ and $20 \mathrm{vol} \%$.

\section{EXPERIMENTAL RESULTS AND DISCUSSION}

\subsection{Temperatures of coal samples and oxygen concentration at outlet in TPS}

The coal pile in the present experiments is a porous medium enabling the oxygen/nitrogen mixture to flow with little resistance presenting also a large surface area available for heat, mass transfer and reactions. In the experiment, the porosity $\emptyset$ of coal samples in the container is estimated by $\emptyset=\left(\rho_{p}-\rho_{b}\right) / \rho_{p}$ to be 0.523 , where $\rho_{p}$ is particle density $\left(1320 \mathrm{~kg} / \mathrm{m}^{3}\right)$ and $\rho_{b}$ bulk density of the coal $\left(630 \mathrm{~kg} / \mathrm{m}^{3}\right)$.

The measured temperature at the center of the container is shown in Fig. 2 against time for various inlet oxygen concentrations together with the temperature of the oven, whereas Fig. 3 shows the difference of temperature between oven and coal in the container $\left(T_{o v}-T\right)$ as derived from Fig. 2. Figure 4 presents the oxygen concentration at the exit of the container and Fig. 5 shows the temperature rise rate of the coal and oven as derived from the data in Fig. 2. 


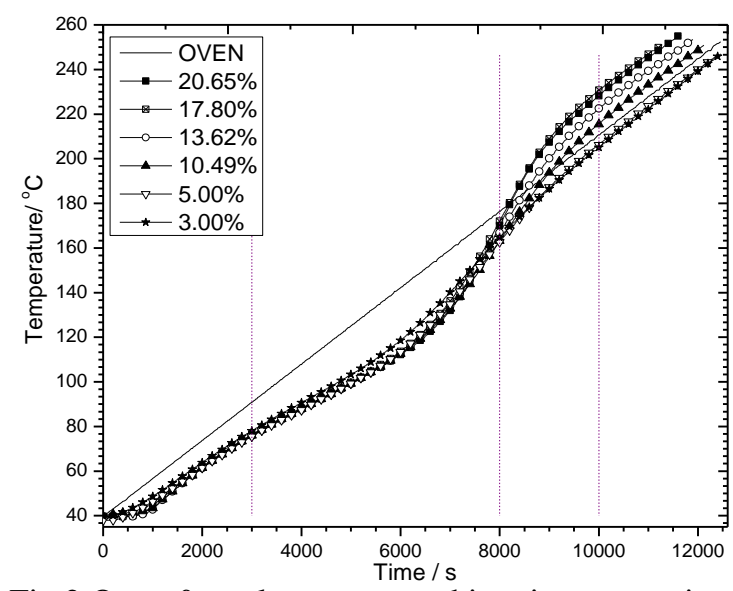

Fig.2 Oven \& coal temperature histories versus time

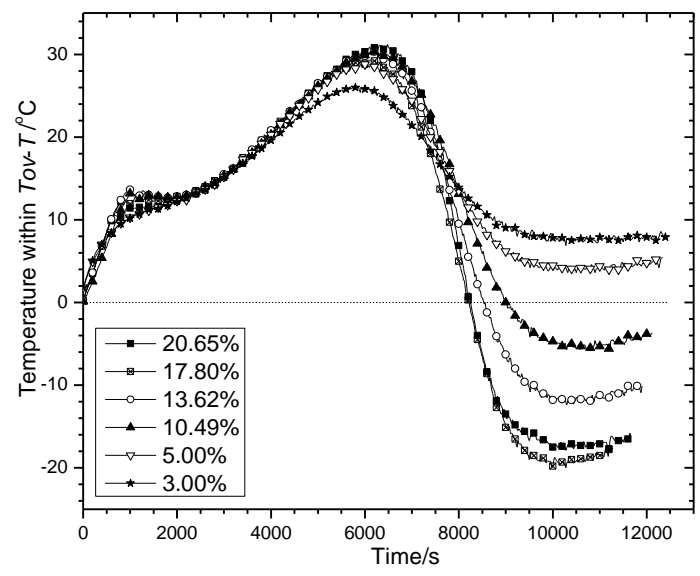

Fig. 3 Temperature difference histories of oven $\&$ coal
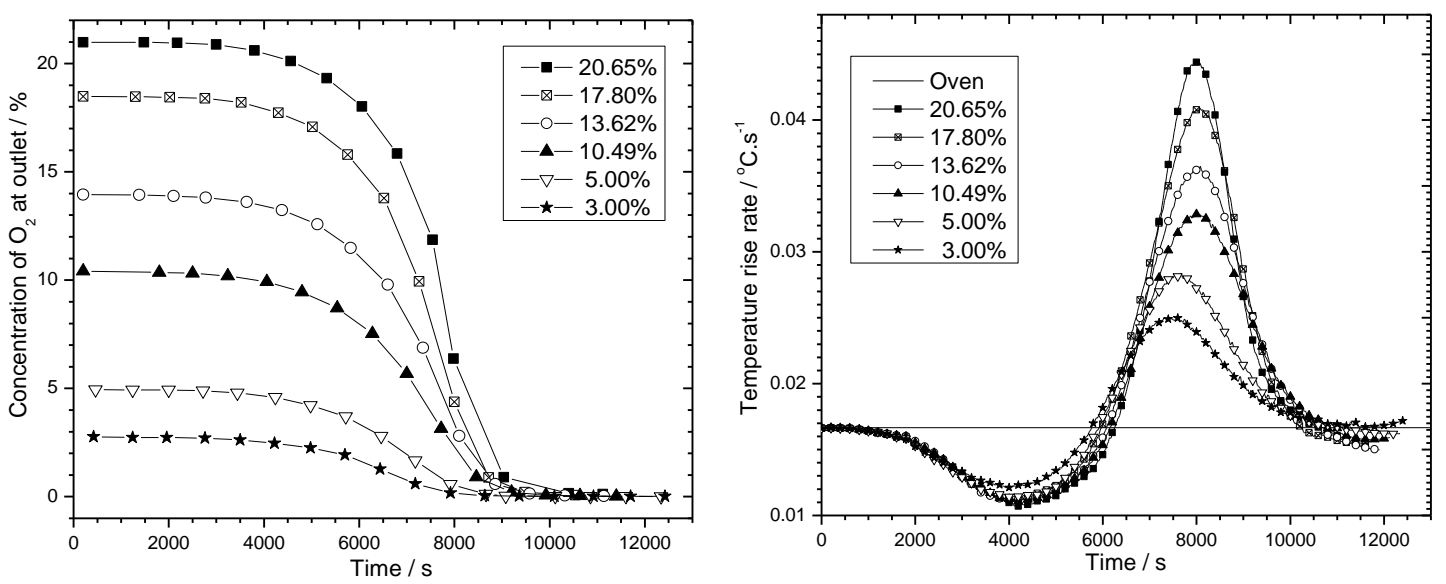

Fig. 4 Oxygen concentration at outlet port versus time

Fig. 5 Temperature rate of rise of coal versus time

\subsection{Results and discussion - TPS}

We can make the following remarks regarding Figs. 2-5:

1) The measured temperature at the center of the container is also the coal temperature which is close to the gas temperature flowing around the particles as we pointed out earlier.

2) At the initial heating period (up to about 3000s) - stage I- shortly after heating starts the coal temperature lags the oven temperature owing to its thermal inertia but the temperature rate of rise is the same as the oven temperature rate of rise (see also Fig.5) because no reactions or moisture evaporation occur.

3) Subsequently the coal temperature drops (3000 to $8000 \mathrm{~s}$ ) - stage II- owing to moisture evaporation and possible endothermic reaction of oxygen by chemisorption. During the period from 0 to $8000 \mathrm{~s}$, there is no much difference in the coal temperature with varying oxygen concentrations.

4) After about 8000 s - stage III- the coal temperature rises owing to exothermic reactions with oxygen ("burn-off"). For this regime, the temperature rise depends strongly on oxygen concentration. Here the CPTs between the oven and coal sample curves are $181.0,181.1,185.8$ and $193.8^{\circ} \mathrm{C}$, respectively, for oxygen concentrations at inlet of $20.65 \%, 17.80 \%, 13.62 \%$ and $10.49 \%$.

5) According to the results of test in Fig. 2, the CPT exists as long as the oxygen concentrations at the inlet is greater than $10.49 \%$, but not for oxygen concentrations less than $5 \%$. 
6) Finally, at much later times $>10000$ seconds - stage IV- , the rate of temperature rise of the coal becomes the same as that of the oven (see Fig.5). The reason is that at this period all oxygen is consumed inside the container (see Fig. 3), thus, providing the same maximum heat release rate for heating the coal pile.

\section{3 Results and discussion - TGA-DSC}

Figure 6 shows the TG and DSC curves under various oxygen concentrations, namely $20 \%, 18 \%, 14 \%$ and $10 \%$ for the initial heating period up to $300{ }^{\circ} \mathrm{C}$ at the heating rate of $10{ }^{\circ} \mathrm{C} / \mathrm{min}$. Figure 7 shows typical detailed TG, DSC and DTG curves versus temperature for oxygen concentration of $20 \%$ in the initial heating period up to $300{ }^{\circ} \mathrm{C}$.

Figure 6 and 7 show that the combustion process of coal contains several stages which correspond to the stages identified in section 3.2, including (stage I) heating of coal sample, (stage II) degassing/dehydration and evaporation, (stage III) weight gain by oxygen adsorption, (stage IV) oxidation and pyrolysis of coal. The results in Table 2 shows that the temperatures associated with all of these stages are slightly increased with decreasing oxygen concentration. These stages correspond closely to the stages of coal pile heating discussed in section 3.2.

Focusing on Fig. 7, we note that the initial weight loss starting from $30^{\circ} \mathrm{C}$ is due to gas desorption (such as $\mathrm{CO}_{2}$ and $\mathrm{CH}_{4}$ ) from the coal interface until the DTG curve achieves the first peak at $69.1{ }^{\circ} \mathrm{C}$; then the rate of weight loss declines but the weight of coal still reduces until $153.8^{\circ} \mathrm{C}$ where the weight loss reaches a minimum because of water evaporating from free water of coal or gases generated by oxidation. From 69.1 ${ }^{\circ} \mathrm{C}$ to $153.8^{\circ} \mathrm{C}$ moisture in coal vaporized inhibits the heating of coal by oxidation and subsequently the heat changes from endothermic to exothermic. Thereafter, the oxidation process of coal accelerates and oxygen is absorbed on the coal surface so that the weight of the coal continues to increase until it peaks at $265.4^{\circ} \mathrm{C}$ This stage corresponds to oxidation of the coal at low temperatures, where oxygen is absorbed on the surface of the coal, which is followed by ignition and burn out after $300{ }^{\circ} \mathrm{C}$.

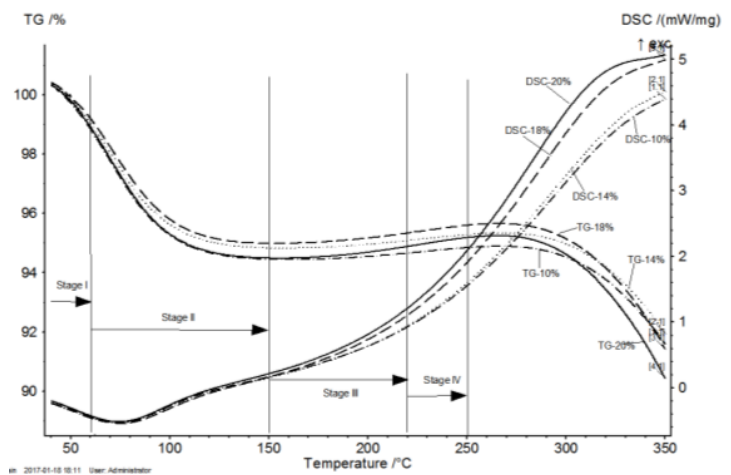

Fig.6 TGA-DSC over various oxygen concentration

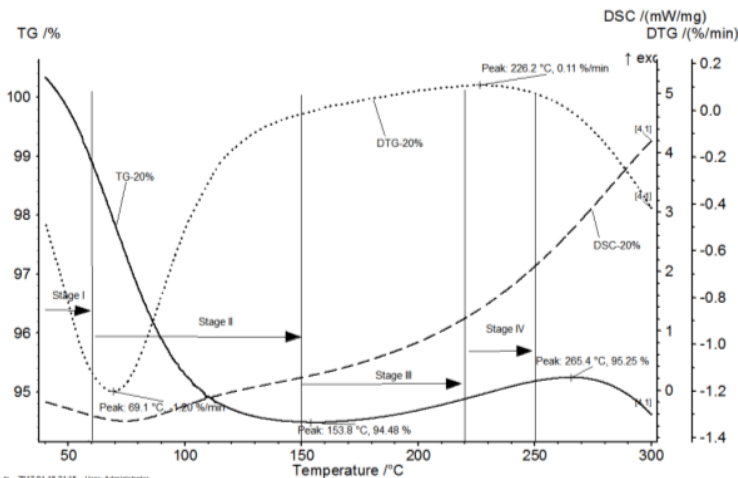

Fig. 7 TGA-DSC curve at $\mathrm{O}_{2}$ of $20 \%$

Table. 2 Typical temperatures of coal oxidation under various oxygen concentrations up to $300{ }^{\circ} \mathrm{C}$

\begin{tabular}{|l|c|c|r|}
\hline Oxygen concentration $/ \mathbf{\%}$ & DTG first peak $/{ }^{\mathbf{}} \mathbf{C}$ & Weight loss peak/ ${ }^{\mathbf{}} \mathbf{C}$ & Weight gain peak $/{ }^{\circ} \mathbf{C}$ \\
\hline 20.00 & 69.1 & 153.8 & 265.4 \\
\hline 18.00 & 70.9 & 152.1 & 265.6 \\
\hline 14.00 & 75.2 & 158.9 & 267.8 \\
\hline 10.00 & 78.4 & 159.6 & 268.1 \\
\hline
\end{tabular}

\section{MATHEMATICAL MODEL AND ANALYSIS}

\section{1 Energy and Oxygen conservation of coal in cylindrical container}

\subsubsection{Energy balance and heat from the coal sample}

In the present experiments, the density of coal and the porosity of the coal samples are nearly constant because consumption of coal is negligible. Therefore, the coal sample in the container is a homogeneous 
porous medium $\left(\varnothing=\left(\rho_{p}-\rho_{b}\right) / \rho_{p}=0.523\right)$. In addition, the temperatures and oxygen concentrations in the container are assumed uniform and equal to the exit conditions because the heating rate in the oven is low $\left(1^{\circ} \mathrm{C} / \mathrm{min}\right)$ so that diffusion has time to create uniform conditions. During the heating, the reaction of oxygen with coal can be described globally as follows:

$$
\text { Coal }+\mathrm{O}_{2} \stackrel{\text { react }}{\longrightarrow} \text { Gaseous Products }(g)+\text { Solid Products }(s)+\text { Energy }
$$

The reaction in Eq. 1 can be exothermic or endothermic within different stages $[14 ; 32]$. Furthermore, the moisture in coal can absorb heat by evaporation as the data in Figs. 3 and 5 shows.

The energy conservation in the container is:

$M C_{p} \frac{d T}{d t}=A h_{c}\left(T_{o v}-T\right)+\dot{m} C_{p}\left(T_{o v}-T\right)+\dot{Q}_{r}$

Here the value of mass of coal $M$ is obtained as $0.04 \mathrm{~kg}$, surface area of the container $A=0.0088 \mathrm{~m}^{2}$, air flow rate $\dot{m}=1.61 \mathrm{E}-06 \mathrm{~kg} / \mathrm{s}$. Note that the heat rate term $\dot{Q}_{r}$ can be zero, positive owing to oxidation or negative owing primarily to coal moisture evaporation.

In order to find out the characteristics of coal oxidation in the container, the heat generating rate $\dot{Q}_{r}$ in Eq. 2 can be rewritten

$$
\dot{Q_{r}}=M C_{p} \frac{d T}{d t}-\left(A h_{c}+\dot{m} C_{p}\right)\left(T_{o v}-T\right)
$$

Therefore the heat generating rate $\dot{Q}_{r}$ over time or temperature of oven could be obtained (Fig. 8) through Eq. 3. In this equation, $\frac{d T}{d t}$ is calculated by the derivative of $T$ with time (shown in Fig.5). Besides, the temperatures of oven and coal samples $\left(T_{o v}\right.$ and $\left.T\right)$ in the test were all measured.

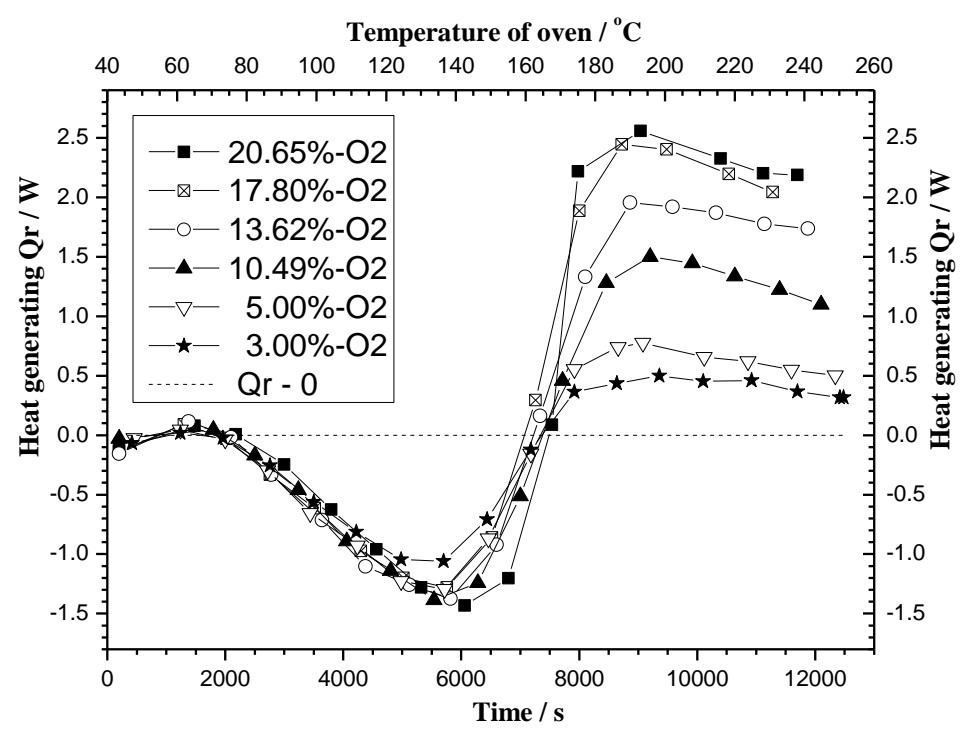

Fig. 8 Heat loss and gain by the coal samples in container over time/temperature owing to moisture evaporation and oxidation at different inlet oxygen concentrations

In view of the results of $\dot{Q}_{r}$ (Fig. 8) and $T$ (Fig. 2), the process of coal oxidation in the experiment could be divided into four stages with respect of temperature rather than time, which, indeed are similar to those identified in section $3.1 \& 3.3$ :

I) The stage with no reaction $\left(\sim<60^{\circ} \mathrm{C}\right)$ where the heat generated by reaction or moisture evaporation is essentially negligible: 
II) The endothermic period $\left(60 \sim 140{ }^{\circ} \mathrm{C}\right)$ where the energy supplied from outside oven is absorbed, by moisture evaporation of coal samples independent of the oxygen concentration supplied which indicates that negligible energy is generated by possible oxidation. Note that the maximum heat loss for the moisture evaporation is about $-1.5 \mathrm{~J} / \mathrm{s}$ and that Stage II lasts about 5000 seconds. The maximum heat loss depends on the moisture fraction and the duration of stage II and on the total moisture mass;

III) An accelerated oxidation period $\left(140 \sim 220^{\circ} \mathrm{C}\right)$ where additional energy is released from coal oxidation which increases with oxygen concentration (Fig. 8) and where the peak value of the energy release is about $2.5 \mathrm{~J} / \mathrm{s}$ for the highest oxygen concentration $20.65 \%$;

IV) A steady oxidation period $\left(>220^{\circ} \mathrm{C}\right)$, where the heat release is a constant for the same oxygen concentration at inlet because all oxygen is consumed inside the container.

\subsubsection{Global oxidation rate parameters}

Next we discuss the oxygen balance in the container. Note that the oxygen concentration inside the container $\left(Y_{O_{2}}\right)$ is equal to the oxygen concentration at the outlet $\left(Y_{O_{2}, \text { out }}\right)$ as we assume uniform mixing inside the coal container, namely

$$
Y_{O_{2}}=Y_{O_{2}, \text { out }}
$$

We assume that oxygen is consumed according to a first order law related to the global reaction in Eq. 1. In the most commonly used form $[24 ; 33 ; 34]$, the reaction rate is based on the mass concentration of $\mathrm{O}_{2}$ in the sample coal pile [11]. Namely, the rate of consumption of $\mathrm{O}_{2}$ per unit volume of the coal sample $\left(r_{\mathrm{O}_{2}}\right.$, $\left.\mathrm{kg} /\left(\mathrm{m}^{3} \mathrm{~s}\right)\right)$ can be expressed as:

$r_{O_{2}}=-\emptyset \rho_{g} Y_{O_{2}} A_{0} \exp \left(-\frac{E_{a}}{R T}\right)$

In this equation the pre-exponential factor may depend on particle size [11].

In addition, the mass conversation of oxygen during process of coal oxidation in the container is:

$m_{O 2} \frac{d Y_{O_{2}}}{d t}=r_{O_{2}} \cdot V+\dot{m}\left(Y_{O_{2}}-Y_{O_{2}}^{0}\right)$

The transient term is neglected because $m_{O 2} \frac{d Y_{O 2}}{d t} \ll r_{O 2} \cdot V$ [22]. Therefore Eq. 6 becomes

$-r_{O 2} \cdot V=\dot{m}\left(Y_{O_{2}}-Y_{O_{2}}^{0}\right)$

Inserting Eq. 5 into Eq. 7 we get:

$$
\emptyset \rho_{g} Y_{O_{2}} A_{0} \exp \left(-\frac{E_{a}}{R T}\right)=\frac{\dot{m}\left(Y_{O_{2}}^{0}-Y_{O_{2}}\right)}{V}
$$

Eq. 8 can be used in conjunction with the results in Fig. 4 and Eq. 4 to determine the activation energy and pre exponential factor for the global oxygen-coal reaction:

$\frac{Y_{O_{2}}^{0}-Y_{O_{2}}}{Y_{O_{2}}}=\frac{V}{\dot{m}} \emptyset \rho_{g} A_{0} \exp \left(-\frac{E_{a}}{R T}\right)$

Or:

$\ln \frac{Y_{O_{2}}^{0}-Y_{O_{2}}}{Y_{O_{2}}}=-\frac{E_{a}}{R T}+\ln \left(\frac{V}{\dot{m}} \emptyset \rho_{g} \cdot A_{0}\right)$

Therefore, the relationship could be obtained between $\ln \frac{Y_{O_{2}}^{0}-Y_{O_{2}}}{Y_{O_{2}}}$ and $\frac{1}{T}$ using the data in Fig.4 and Eq.5 so that the activation energy and pre-exponential factor can be obtained from the slope and intercept of such a plot. The results in Fig. 9 show that $E_{a}$ varies from $82 \mathrm{~kJ} / \mathrm{mol}$ to $90 \mathrm{~kJ} / \mathrm{mol}$, and $A_{0}$ from $0.3 \mathrm{E}+10$ and $2.2 \mathrm{E}+10$ $\mathrm{s}^{-1}$. Despite the differences (especially for $A_{0}$ ), the average values of $86.92 \mathrm{~kJ} / \mathrm{mol}$ and $1.12 \mathrm{E}+10 \mathrm{~s}^{-1}$ for activation energy and pre-exponential factor respectively are used in the analysis in section 4.2. 


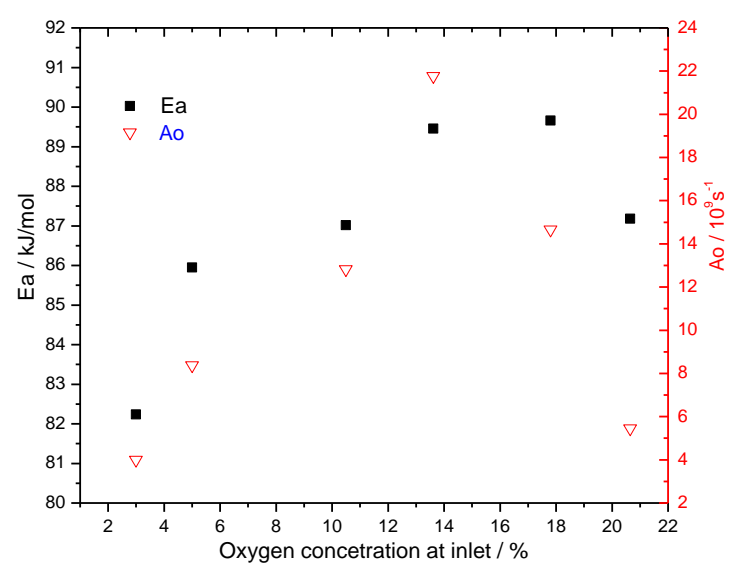

Fig. 9 Values of $E_{a}$ and $A_{0}$ vs. inlet oxygen concentration according to Eq.10

\subsubsection{Heat released per mass of oxygen consumed $\Delta H_{O 2}$}

The heat generated by oxidation can be expressed as:

$\dot{Q_{r}}=\dot{m}\left(Y_{O_{2}}^{0}-Y_{O_{2}}\right) \cdot \Delta H_{O 2}=\emptyset \rho_{g} Y_{O_{2}} V \cdot \Delta H_{O 2} \cdot A_{0} \exp \left(-\frac{E_{a}}{R T}\right)$

This value for stage IV where all oxygen is consumed inside the container and all moisture has evaporated is (compare also Fig.8):

$$
\dot{Q_{r}}=\dot{m} \cdot Y_{O_{2}}^{0} \cdot \Delta H_{O 2}
$$

According to Eq. 3 and Eq. $11 \mathrm{~b}$, the reaction enthalpy of $\mathrm{O}_{2}, \Delta H_{O 2}$, is

$\Delta H_{O 2}=\frac{M C_{p} \frac{d T}{d t}-\left(A h_{c}+\dot{m} C_{p}\right)\left(T_{o v}-T\right)}{\dot{m} \cdot Y_{O_{2}}^{0}}$

The heat release rate per unit mass of oxygen is calculated for the data in stage IV to be $6820 \mathrm{~kJ} / \mathrm{kg}$ independent of inlet oxygen concentration.

\subsection{Solution of global energy equation 2 neglecting the moisture cooling effect}

Note that the oxygen concentration inside the container $\left(Y_{O_{2}}\right)$ is obtained from Eq. 11a as:

$$
Y_{O_{2}}=\frac{\dot{m} Y_{O 2}^{0}}{\dot{m}+\emptyset \rho_{g} V A_{0} \exp \left(-\frac{E_{a}}{R T}\right)}
$$

By inserting Eq. 11a into Eq. 2, the energy conservation equation in the container is written as follows:

$\frac{d T}{d t}=\frac{\left(A h_{c}+\dot{m} C_{p}\right)\left(T_{o v}-T\right)}{M C_{p}}+\frac{1}{M C_{p}} \frac{\dot{m} Y_{O{ }_{2}}^{0} \Delta H_{O 2}}{\frac{\dot{m}}{\phi \rho_{g} V A_{0} \exp \left(-\frac{E a}{R T}\right)}+1}$

Next we define the following parameters of the system:

a. Thermal residence time $\tau=\frac{M C_{p}}{\left(h_{c} A+\dot{m} C_{p}\right)}$;

b. The dimensionless coal bed temperature $X=\frac{T-T_{0}}{\alpha \tau}$, where $\alpha$ is the heating rate in the oven, namely $T_{o v}-T_{0}=\alpha t$

c. The dimensionless time $\tilde{t}=\frac{t}{\tau}$;

d. The normalised maximum heat release $B=\frac{\dot{m} Y_{O_{2}}^{0} \Delta H_{O 2}}{\alpha M C_{p}}$; 
e. A Damkohler number $D a=\frac{\phi \rho_{g} V A_{0} \exp \left(-\frac{E a}{R T}\right)}{\dot{m}}=\frac{\tau_{f}}{\tau_{c h}}=\frac{\text { flow time }}{\text { chemical time }}$ is also presented [35], where $\tau_{f}=\frac{\phi \rho_{g} V}{\dot{m}}$ and $\tau_{c h}=\frac{1}{A_{0}} \exp \left(\frac{E_{a}}{R T}\right)$.

Using these definitions Eq.14 becomes:

$\frac{d X}{d \tilde{t}}=(\tilde{t}-X)+\frac{B}{\frac{1}{D a}+1}$

The boundary condition is $X=0$ at $\tilde{t}=0$. By noting $T=T_{0}+a \tau \cdot X$, an implicit solution of Eq. 15 is written as:

$X=e^{-\tilde{t}}+\tilde{t}-1+B \int_{0}^{\tilde{t}} \frac{D a}{1+D a} e^{t-\tilde{t}} d t$

This equation has two limits that do not depend on the moisture evaporation, namely the first limit is for small times where both oxidation and moisture are not acting (stage I, section 3.2) and the second limit occurs at large times (stage IV, section 3.2) where all oxygen is consumed inside the container providing all its combustion energy and coal moisture has disappeared by evaporation in stage II.

In the first regime, stage I, the reaction rate is zero ( $D a$ is also nearly zero) and the solution Eq. 16a becomes

$$
X=e^{-\tilde{t}}+\tilde{t}-1
$$

In the stage IV, the value of $D a$ is large so that $\frac{D a}{1+D a}=1$ and Eq.16a becomes

$$
X=e^{-\tilde{t}}+\tilde{t}-1+B\left(1-e^{-\tilde{t}}\right)
$$

For low temperatures (in steady state stage I) the value of dimensionless time $\tilde{t}$ is large and the term $e^{-\tilde{t}}$ is negligible. Therefore, Eq. 16b gives in terms of primitive variables (see definitions following Eq.14) the following relation between the oven and coal sample temperature:

$$
\left(T_{o v}-T\right)_{i}=\alpha \tau
$$

Also, for large times (at large value of dimensionless time of stage IV), the value of $e^{-\tilde{t}}$ is nearly close to zero, Eq. 16c takes the form (stage IV)

$$
\left(T_{o v}-T\right)_{i v}=\alpha \tau(1-B)
$$

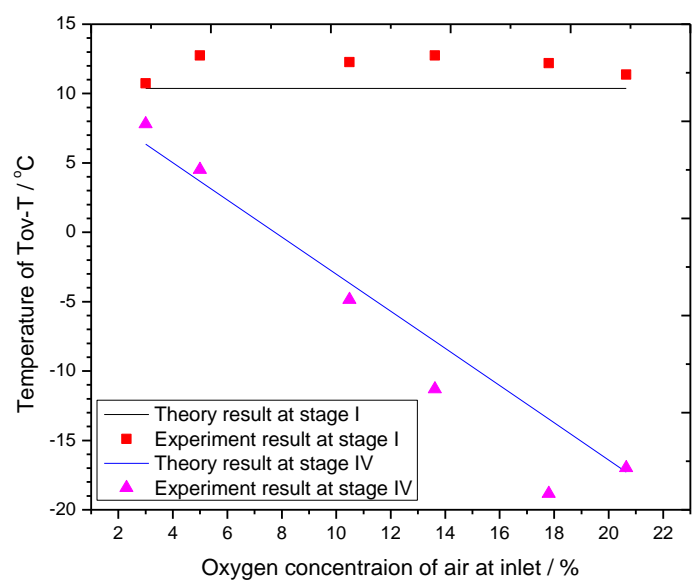

Fig. 10 Differences of temperature between oven and coal at stages I \& IV against inlet oxygen concentration; comparison of theory (Eqs.17a and 17b) and experiment (Fig. 2)

These results agree well with the experimental values as illustrated in Fig. 10 and also can be deduced from Fig. 2. We note that the values of $\alpha$ and $\tau$ in this work are $0.0167^{\circ} \mathrm{C} / \mathrm{s}$ and $623 \mathrm{~s}$. In addition, $B$ takes the 
following values for each inlet oxygen concentration (from $3.00 \%$ to $20.65 \%$, in Fig. 10) $0.39,0.65,1.35$, $1.76,2.30$ and 2.66 respectively.

We note from Eq. 17b and comparison with the experiments (Fig. 10) that crossover would occur when $T>T_{o v}$ which leads to the important conclusion that $B$ must be greater than one $(\mathrm{B}>1)$ regardless of the moisture content.

In addition, we have solved numerically and asymptotically Eqs.15-16a for the crossover temperature (neglecting cooling by moisture evaporation) by using the relation that at this point $X=\tilde{t}$. The so found crossover temperature (dependent on the $D a$ number) is less than the experimental value shown in Fig. 2 which is expected because in the current Eq. 15 we have neglected the heat removed by evaporation in Stage II. Note that the maximum heat loss for the moisture evaporation is $-1.5 \mathrm{~J} / \mathrm{s}$ and that Stage II lasts about 5000 seconds (Fig. 8). The maximum heat loss depends on the moisture fraction and the duration of stage II on the total moisture mass. We will present CPT results for Eq. 15 in a subsequent publication including semi- empirical modeling of moisture evaporation dominating stage II.

\section{SUMMARY AND CONCLUSIONS}

The Temperature-Programmed method (TPS in Fig. 1) for testing the propensity to self-ignition and the oxidation performances of the bituminous coal was used for varying oxygen concentrations below the ambient. Coal samples with sieved size $0.3 \sim 0.45 \mathrm{~mm}$ located in a cylindrical container (diameter $=45 \mathrm{~mm}$, height $=40 \mathrm{~mm}$ ) were heated in the TPS oven at a constant heating rate $1{ }^{\circ} \mathrm{C} / \mathrm{min}$. A constant flow rate at different oxygen concentrations is supplied at the bottom of the container and the products of oxidation exit at the top. As the coal samples are heated in the container within the TPS, the concentration histories of the gaseous products are measured as well as the temperature history at the center of the container. The CPT is the temperature (temperature and corresponding time) at which the increasing coal temperature is equal to the increasing oven temperature. It was found that crossover occurred for inlet oxygen concentrations between $10.49 \%$ and $20.95 \%$ (ambient) but not for $5 \%$ and $3 \%$ oxygen concentration. We note that moisture in coal particles and humidity of gas flow affect the crossing point temperature (Figs 2-5 and discussion in section 3.2).

In order to evaluate the heating characteristics of the coal, a mathematical model was proposed. Based on dimensionless form of the energy conservation equation, critical parameters are obtained to describe the stages of coal heating, dehydration and oxidation.

1) From exit and inlet oxygen concentrations in the experiments, the TPS method provides an apparent global activation energy $\left(E_{a}\right)$ and pre-exponential factor $\left(A_{0}\right)$ for the coal oxidation.

2) In order to normalize several factors affecting the coal oxidation, the critical parameters such as the moisture content of the coal particles, the normalised maximum heat release $\left(B=\frac{\dot{m} Y_{O_{2}}^{0} \Delta H_{O 2}}{\alpha M C_{p}}\right)$ and the Damkohler number $D a=\frac{\phi \rho_{g} V A_{0} \exp \left(-\frac{E a}{R T}\right)}{\dot{m}}$ were proposed based on the CPT method. Furthermore, via the heating rate of coal particles during the coal spontaneous combustion, the reaction enthalpy of oxygen $\Delta H_{O 2}$ is obtained to be $6820 \mathrm{~kJ} / \mathrm{kg}$.

3) In accordance with the heat generating rate of coal, four stages of spontaneous combustion of coal were divided as: stage I without reaction $\left(\sim 60{ }^{\circ} \mathrm{C}\right)$, stage II endothermic phase (including dehydration, $60 \sim 140^{\circ} \mathrm{C}$ ) which is affected by the moisture content, stage III accelerated exothermic phase $\left(140 \sim 220^{\circ} \mathrm{C}\right)$ in which CPT would occur and stage IV which is a steady exothermic stage $\left(220 \sim 260^{\circ} \mathrm{C}\right.$ ) with all oxygen consumed inside the TPS sample container.

4) At stages I and IV, the temperature differences between oven and coal curves are constant determined by the parameters of $\alpha \tau$ and $(B-1) \cdot \alpha \tau$ respectively in agreement with the model (Eq.17a and Eq.17b and Fig.10).

5) For a crossing point to occur between the oven and coal temperatures, the crossover condition is that $B=\frac{\dot{m} Y_{O_{2}}^{0} \Delta H_{O 2}}{\alpha M C_{p}}$ must be greater than one $(B>1)$ independently of moisture content in coal. 
6) The effects of moisture on the Crossing-Point Temperature will be discussed quantitatively in another paper.

\section{ACKNOWLEDGMENT}

The authors wish to acknowledge the financial support of the National Natural Science Foundation of China (Nos. 51304071, 51304073 and U1361205). The authors would also like to thank the China Scholarship Council to sponsor the authors of Yong-liang XU and Lan-yun WANG studying in UK.

\section{REFERENCES}

[1] Prakash, A., \& Gupta, R. P. (1999). Surface fires in Jharia coalfield, India-their distribution and estimation of area and temperature from TM data. International Journal of Remote Sensing, 20(10), 1935-1946. doi:http://dx.doi.org/10.1080/014311699212281

[2] Stracher, G. B., \& Taylor, T. P. (2004). Coal fires burning out of control around the world: thermodynamic recipe for environmental catastrophe. International Journal of Coal Geology, 59(1-2), 7-17. doi:http://dx.doi.org/10.1016/j.coal.2003.03.002

[3] Roy, D., Gautam, S., Singh, P., Singh, G., Das, B. K., \& Patra, A. K. (2016). Carbonaceous species and physicochemical characteristics of PM10 in coal mine fire area-a case study. Air Quality, Atmosphere \& Health, 9(4), 429-437. doi:http://dx.doi.org/10.1007/s11869-015-0355-2

[4] Kuenzer, C., \& Stracher, G. B. (2012). Geomorphology of coal seam fires. Geomorphology, 138(1), 209-222. doi:http://dx.doi.org/10.1016/j.geomorph.2011.09.004

[5] Elick, J. M. (2011). Mapping the coal fire at Centralia, Pa using thermal infrared imagery. International Journal of Coal Geology, 87(3-4), 197-203. doi:http://dx.doi.org/10.1016/j.coal.2011.06.018

[6] Elick, J. M. (2013). The effect of abundant precipitation on coal fire subsidence and its implications in Centralia, PA. International Journal of Coal Geology, 105, 110-119. doi:http://dx.doi.org/10.1016/j.coal.2012.10.004

[7] Song, Z., \& Kuenzer, C. (2014). Coal fires in China over the last decade: A comprehensive review. International Journal of Coal Geology, 133, 72-99. doi:http://dx.doi.org/10.1016/j.coal.2014.09.004

[8] J. C. Jones, K. P. H., J. Littlefair and S. Rennie. (1998). Kinetic parameters of oxidation of coals by heatrelease measurement and their relevance to self-heating tests. Fuel, 77(1/2), 19-22. doi:http://dx.doi.org/10.1016/s0016-2361(97)00155-5

[9] Jones, J. C., Chiz, P. S., Koh, R., \& Matthew, J. (1996). Kinetic parameters of oxidation of bituminous coals from heat-release rate measurements. Fuel, 75(15), 1755-1757. doi:http://dx.doi.org/10.1016/S0016-2361(96)00159-7

[10] Wang, H., Dlugogorski, B. Z., \& Kennedy, E. M. (1998). Low-temperature oxidation of coal at elevated pressures. Journal of Loss Prevention in the Process Industries, 11(6), 373-381. doi:http://dx.doi.org/10.1016/S0950-4230(98)00020-5

[11] Zarrouk, S. J., O'Sullivan, M. J., \& George, J. D. S. (2006). Modelling the spontaneous combustion of coal: The adiabatic testing procedure. Combustion Theory \& Modelling, 10(6), 907-926. doi:http://dx.doi.org/10.1080/13647830600644456

[12] Beamish, B. B., Lau, A. G., Moodie, A. L., \& Vallance, T. A. (2002). Assessing the self-heating behaviour of Callide coal using a 2-metre column. Journal of Loss Prevention in the Process Industries, 15(5), 385-390. doi:http://dx.doi.org/10.1016/S0950-4230(02)00020-7

[13] Beamish, B. B. (2005). Comparison of the R70 self-heating rate of New Zealand and Australian coals to Suggate rank parameter. International Journal of Coal Geology, 64(1-2), 139-144. doi:http://dx.doi.org/10.1016/j.coal.2005.03.012

[14] Arisoy, A., \& Beamish, B. (2015). Reaction kinetics of coal oxidation at low temperatures. Fuel, 159, 412-417. doi:http://dx.doi.org/10.1016/j.fuel.2015.06.054

[15] Yang, Y. L., Zeng-Hua, L. I., Pan, S. K., Gao, S. Y., \& Wang, Y. L. (2009). Oxidative heat release intensity in coal at low temperatures measured by the hot-wire method. Mining Science \& Technology, 19(3), 326-330. doi:http://dx.doi.org/10.1016/s1674-5264(09)60061-2

[16] Yang, Y., Li, Z., Hou, S., Gu, F., Gao, S., \& Tang, Y. (2014). The shortest period of coal spontaneous combustion on the basis of oxidative heat release intensity. International Journal of Mining Science and Technology, 24(1), 99-103. doi:http://dx.doi.org/10.1016/j.ijmst.2013.12.017 
[17] Chen, X. D., \& Chong, L. V. (1998). Several Important Issues Related to the Crossing-Point Temperature (CPT) Method for Measuring Self-Ignition Kinetics of Combustible Solids. Process Safety and Environmental Protection, 76(2), 90-93. doi:http://dx.doi.org/10.1205/095758298529380

[18] Sensogut, C., \& Cinar, I. (2000). A ressearch on the Spontaneous Combustion Tendency of Turkish Coals-Ilgin Lignite's Case. Mineral Resources Engineering, 09(04), 9-14. doi:http://dx.doi.org/10.1142/S0950609800000342

[19] Qi, X., Xin, H., Wang, D., \& Qi, G. (2013). A rapid method for determining the R70 self-heating rate of coal. Thermochimica Acta, 571, 21-27. doi:http://dx.doi.org/10.1016/j.tca.2013.08.008

[20] Xu, Y. L., Wang, D. M., Wang, L. Y., Zhong, X. X., \& Chu, T. X. (2012). Experimental research on inhibition performances of the sand-suspended colloid for coal spontaneous combustion Safety Science, 50(4), 822-827. doi:http://dx.doi.org/10.1016/j.ssci.2011.08.026

[21] Wang, D. M., Qi, X. Y., Zhong, X. X., \& Gu, J. J. (2009). Test method for the propensity of coal to spontaneous combustion. Procedia Earth \& Planetary Science, 1(1), 20-26. doi:http://dx.doi.org/10.1016/j.proeps.2009.09.006

[22] Deng, J., Xiao, Y., Li, Q., Lu, J., \& Wen, H. (2015). Experimental studies of spontaneous combustion and anaerobic cooling of coal. Fuel, 157, 261-269. doi:http://dx.doi.org/10.1016/j.fuel.2015.04.063

[23] Fierro, V., Miranda, J. L., Romero, C., Andrés, J. M., Arriaga, A., Schmal, D., \& Visser, G. H. (1999). Prevention of spontaneous combustion in coal stockpiles: Experimental results in coal storage yard. Fuel Processing Technology, 59(1), 23-34. doi:http://dx.doi.org/10.1016/S0378-3820(99)00005-3

[24] Wang, H., Dlugogorski, B. Z., \& Kennedy, E. M. (2003). Coal oxidation at low temperatures: oxygen consumption, oxidation products, reaction mechanism and kinetic modelling. Progress in Energy and Combustion Science, 29(6), 487-513. doi:http://dx.doi.org/10.1016/S0360-1285(03)00042-X

[25] Nimaje, D. S., \& Tripathy, D. P. (2016). Characterization of some Indian coals to assess their liability to spontaneous combustion. Fuel, 163, 139-147. doi:http://dx.doi.org/10.1016/j.fuel.2015.09.041

[26] Krishnaswamy, S., Agarwal, P. K., \& Gunn, R. D. (1996). Low-temperature oxidation of coal. 3. Modelling spontaneous combustion in coal stockpiles. Fuel, 75(3), 353-362. doi:http://dx.doi.org/10.1016/0016-2361(95)00249-9

[27] Taraba, B., Michalec, Z., Blejchař, T., Bojko, M., \& Kozubková, M. (2014). CFD simulations of the effect of wind on the spontaneous heating of coal stockpiles. Fuel, 118(1), 107-112. doi:http://dx.doi.org/10.1016/j.fuel.2013.10.064

[28] Zhang, J., Liang, Y., Ren, T., Wang, Z., \& Wang, G. (2016). Transient CFD modelling of lowtemperature spontaneous heating behaviour in multiple coal stockpiles with wind forced convection. Fuel Processing Technology, 149, 55-74. doi:http://dx.doi.org/10.1016/j.fuproc.2016.04.011

[29] Zhu, J., He, N., Li, D., Zhu, J., He, N., \& Li, D. (2012). The relationship between oxygen consumption rate and temperature during coal spontaneous combustion. Safety Science, 50(4), 842-845. doi:http://dx.doi.org/10.1016/j.ssci.2011.08.023

[30] Sujanti, W., Zhang, D. K., \& Chen, X. D. (1999). Low-temperature oxidation of coal studied using wire-mesh reactors with both steady-state and transient methods. Combustion \& Flame, 117(3), 646651. doi:http://dx.doi.org/10.1016/s0010-2180(98)00139-4

[31] Zhan, J., Wang, H., Zhu, F., \& Song, S. (2014). Analysis on the Governing Reactions in Coal Oxidation at Temperatures up to $400^{\circ} \mathrm{C}$. International Journal of Clean Coal \& Energy, 03(2), 19-28. doi:http://dx.doi.org/10.4236/ijcce.2014.32003

[32] Zhang, J., Ren, T., Liang, Y., \& Wang, Z. (2016). A review on numerical solutions to self-heating of coal stockpile: Mechanism, theoretical basis, and variable study. Fuel, 182, 80-109. doi:http://dx.doi.org/10.1016/j.fuel.2016.05.087

[33] Brooks, K., Svanas, N., \& Glasser, D. (1988). Evaluating the risk of spontaneous combustion in coal stockpiles. Fuel, 67(5), 651-656. doi:http://dx.doi.org/10.1016/0016-2361(88)90293-1

[34] Gong, R., Burnell, J., \& Wake, G. (1999). Modelling spontaneous combustion in wet lignite. Combustion Theory \& Modelling, 3(2), 215-232. doi:http://dx.doi.org/10.1088/1364-7830/3/2/001

[35] Bidabadi, M., Haghiri, A., \& Rahbari, A. (2010). The effect of Lewis and Damköhler numbers on the flame propagation through micro-organic dust particles. International Journal of Thermal Sciences, 49(3), 534-542. doi:http://dx.doi.org/10.1016/j.ijthermalsci.2009.10.002 
